\title{
Chromosome Variation in Three Species of the Marine Gastropod Nucella
}

\author{
Muzammil Ahmed \\ Institute of Marine Biology, University of Karachi, Pakistan
}

Received February 6, 1973

Our knowledge of the cytogenetics of marine molluscs is fragmentary. The one outstanding contribution to this field of study is that of Staiger (1954) who analysed the cytogenetic structure of the wild, pure and hybrid, microgeographical populations of the dogwhelk Nucella (=Thais, Purpura) lapillus from the coast of Brittany in northern France. These populations reveal an adaptive chromosomal polymorphism involving a Robertsonian system. The present study was undertaken to see whether any of the other species of Nucella possessed an equivalent polymorphism.

The three species chosen-Nucella lamellosa, $N$. lima $(=N$. emarginata $)$ and $N$. canaliculata-abound on the Pacific coast of North America and enjoy widespread distribution. They possess, as does $N$. lapillus, a non-pelagic development so that snails hatch from egg capsules as crawling miniatures. This results in microgeographical and geographical isolation which in turn is conducive to population differentiation.

\section{Material and methods}

Chromosome plates were obtained from male and female gonads, somatic cells (after colchicine treatment) and the spawned eggs contained in egg capsules. Snails and egg capsules were collected from several sheltered and exposed shores in the State of Washington and to some extent from Oregon and California. The sodium citrate $(1 \%$ solution) pretreatment method for mammalian chromosomes (Meredith 1969) worked well with snail testicular material. Eggs and egg capsules were fixed in 1:3 acetic alcohol. Before staining and squashing the yolk was extracted from them by treating with a 1:1 mixture of ethyl/methyl alcohol and chloroform (for about 8 hours). The application of colchicine $(2-4 \mathrm{ml}$ of an $0.5 \%$ solution in $400-500 \mathrm{ml}$ of sea water) for inhibiting mitosis in cleaving eggs or somatic tissues of juvenile snails provided an occasional C-metaphase. A $1 \%$ solution of aceto-orcein was routinely used for staining and the chromosomes picked up a light colour. Other stains such as acetocarmine and lacto-propionic orcein produced similar results. Eggs were stained for 2-8 hours and sometimes left to stain overnight

1 Part of a thesis submitted to the University of Washington, Seattle, in partial fulfilment of the requirements for the degree of Doctor of Philosophy. 
in order to soften them. Eggs of $N$. lamellosa and $N$. canaliculata required longer treatment than those of $N$. lima because of greater quantity of yolk and larger size. Photomicrographs were taken on a Zeiss photomicroscope using phase contrast illumination. In view of the large chromosome number in the three species, all chromosomes could not be brought to the same focus for photographing and,therefore, camera lucida drawings of important plates were prepared.

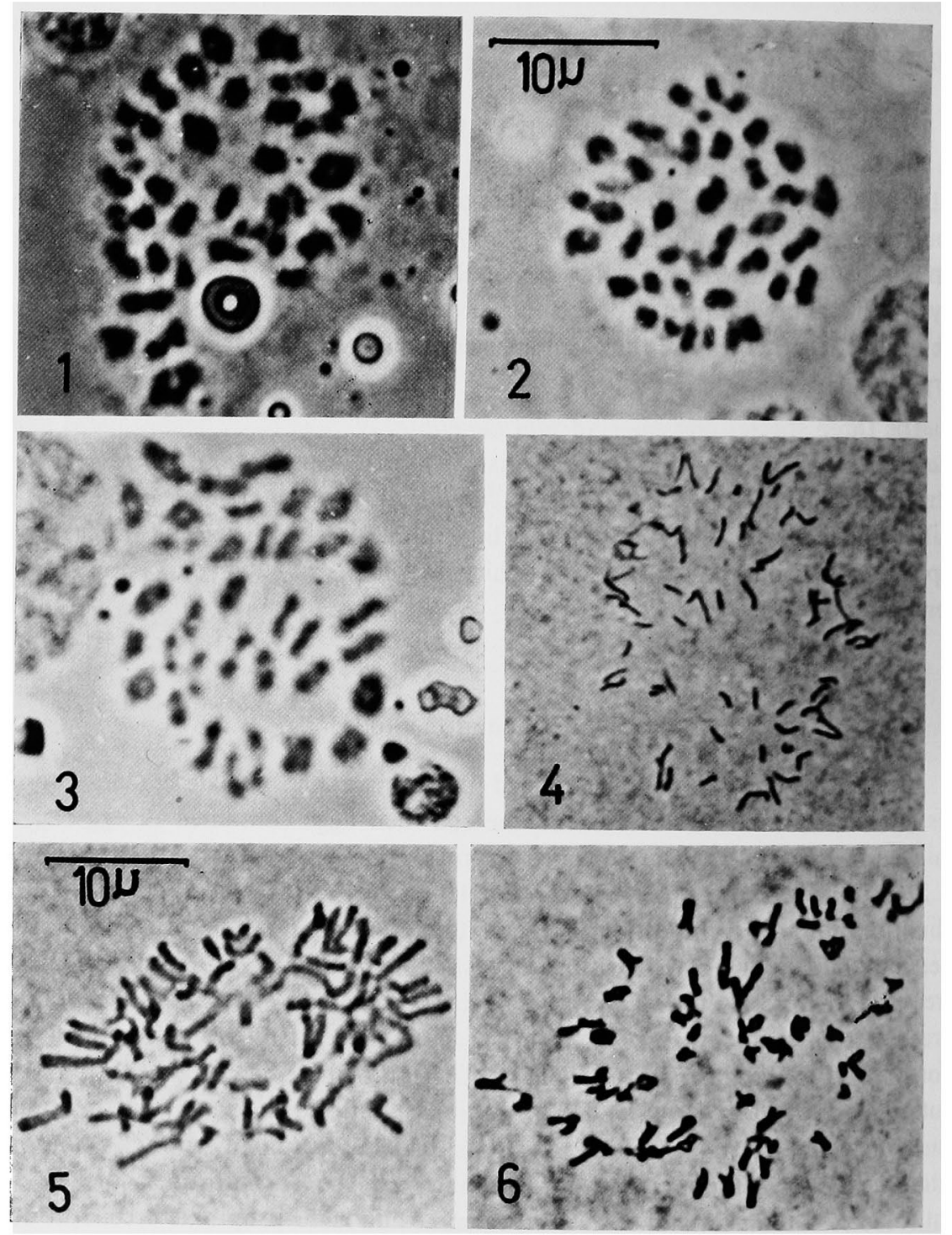

Figs. 1-6. 1-3. Diakinesis bivalents in spermatocytes. Phase contrast. 1, N. lamellosa. $2, N$. lima. 3, N. canaliculata. 4-6. Mitotic metaphases (polar views) from cleaving eggs. Phase contrast. 4, $N$. lamellosa. 5, $N$. lima. $6, N$. canaliculata. Chromosomes with one end bifurcated are telocentrics. 


\section{Observations}

\section{Sample size}

Chromosomes of 5 males of each of the three species were examined. The cytological material of the females came from 327 specimens of $N$. lamellosa, 105 of $N$. lima and 21 of $N$. canaliculata. Although cytological observations were made from all specimens mentioned above, prometaphases and first metaphases (in eggs) were available in only 128 specimens of $N$. lamellosa, 46 of $N$. lima and 10 of $N$. canaliculata. Only 5-10 meiotic plates were generally examined from one specimen but from some as many as 20 were scored. Most of the data and observations reported are, however, based on analysis of prometaphases from oocytes.

\section{Meiosis and mitosis}

In testicular squashes various stages of spermatogenesis were abundantly available although stages of meiotic prophase such as leptotene, zygotene and pachytene
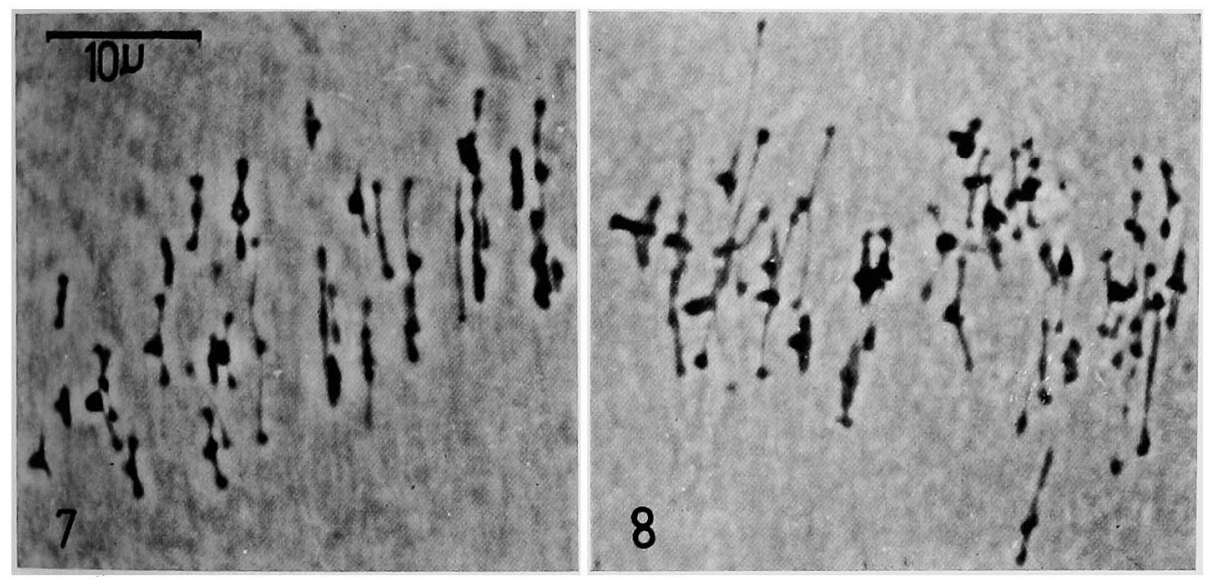

Figs. 7-8. First metaphases. Phase contrast. 7, N. lamellosa. 8, N. lima.

were not distinguished. The chromosomes in spermatocytes were blocked at diakinesis (Figs. 1-3). Meiosis seemed to be chiasmate although most of the bivalents are terminally associated; presumably, therefore, chiasmata are distally localised. Chromosomes in normal oocytes (compared to nurse eggs which occur in N. lima) are at diakinesis at the time of deposition of egg capsules. Diakinesis in oocytes is succeeded by a characteristic prometaphase stage in which bivalents are greatly stretched. First metaphase (Figs. 7-8), first anaphases and formation of polar bodies were observed. Meiosis is completed in about one and a half hours after deposition of the egg capsules and is followed by the first cleavage mitosis (Figs. 4-6).

Very high egg mortality is known to occur in all three species but is most marked in $N$. lima and least marked in $N$. canaliculata. Such mortality is probably caused by several abnormalities such as chromosome clumping and stickiness, fragmentation, multipolar and deformed spindles in mitosis and failure of cleavage. All 
of these were observed in $N$. lima and to a lesser extent in the other two species.

3. Chromosome number

In exceptionally good diakinesis plates in spermatocytes (Figs. $1-3) 35(2 n=70)$ bivalents or bivalent-like bodies could be counted. The diploid number in oocytes and cleaving eggs is also 70 (Figs. 4-8) (Ahmed and Sparks 1970 a). Numerical deviations from $n=35$ were present in about $4 \%$ (30 out of 750) meiotic complements in oocytes of $N$. lamellosa and will be discussed in detail later.

4. Chromosome morphology

The bivalents in the diakinesis plates of spermatocytes were usually rod-like or dumbell-shaped and ring-bivalents were also sometimes visible (Figs. 1-3). Chiasmata were terminal in ring-bivalents but in rods both interstitial and terminal chiasmata were seen. Chiasmata were absent in some cases. Here closely opposing

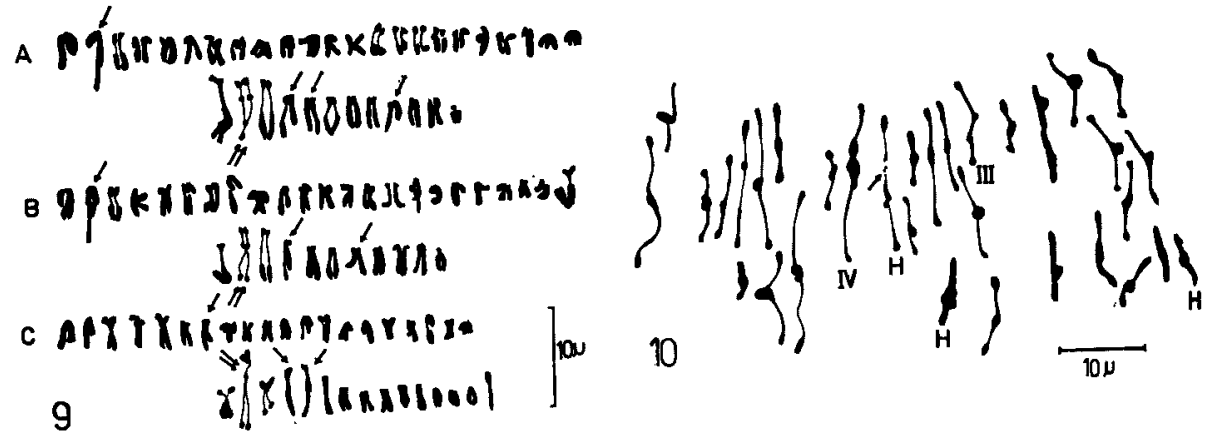

Figs. 9-10. 9, first anaphase half-bivalents of $N . \operatorname{lima}$; half-bivalents with outstandingly unequal chromatids are marked by one arrow, two arrows indicate possible sex-chromosomes. The element placed at the end of row 1 in set $B$ is a translocation bearing element; note that only 34 half-bivalents are present. 10 , prometaphase of $N$. lamellosa. 32 rod II $+1 \mathrm{III}+1 \mathrm{IV}(\mathrm{n}=35+1)$; arrow indicates precociously condensed segment; $\mathrm{H}=$ heteromorphic. A majority of prometaphase and first metaphase complements of this species are of this kind, that is, bear only rod-bivalents.

univalents were present. Since contracted bivalents measure only 1-3 $\mu$ they are not easily analysed. At prometaphase and first metaphase of oocytes, however, the largest rod-bivalents measured some $40-50 \mu$ a consequence of the extreme prometaphase stretching. In several prometaphases and first metaphases of all three species one or more associations of two and occasionally of three bivalents were observed (Figs. 11, 14, 17, and 19). The associations of two bivalents could be broadly grouped as side-to-side, end-to-end, end-to-chiasma and as random associations at interstitial regions. Occasionally two or three bivalents were interconnected by strands of chromatin-like material (Figs. 14 and 17). A majority of these associations were undoubtedly secondary associations of the kind which Staiger (1954) had observed in $N$. lapillus.

The chromosomes were characterized as metacentrics (M), submetacentrics (S), acrocentrics (A) and telocentrics (T). Rod and ring-bivalents had the constitution TT (both ends pointed and tapering), TA (one end pointed other knob- 
like), AA (both ends knob-like), MM, SS and MS. Numerous asymmetrical bivalents, with pairing chromosomes unequal and chiasmata asymmetrically placed, were observed at diakinesis and first metaphase. Such bivalents were reported to be
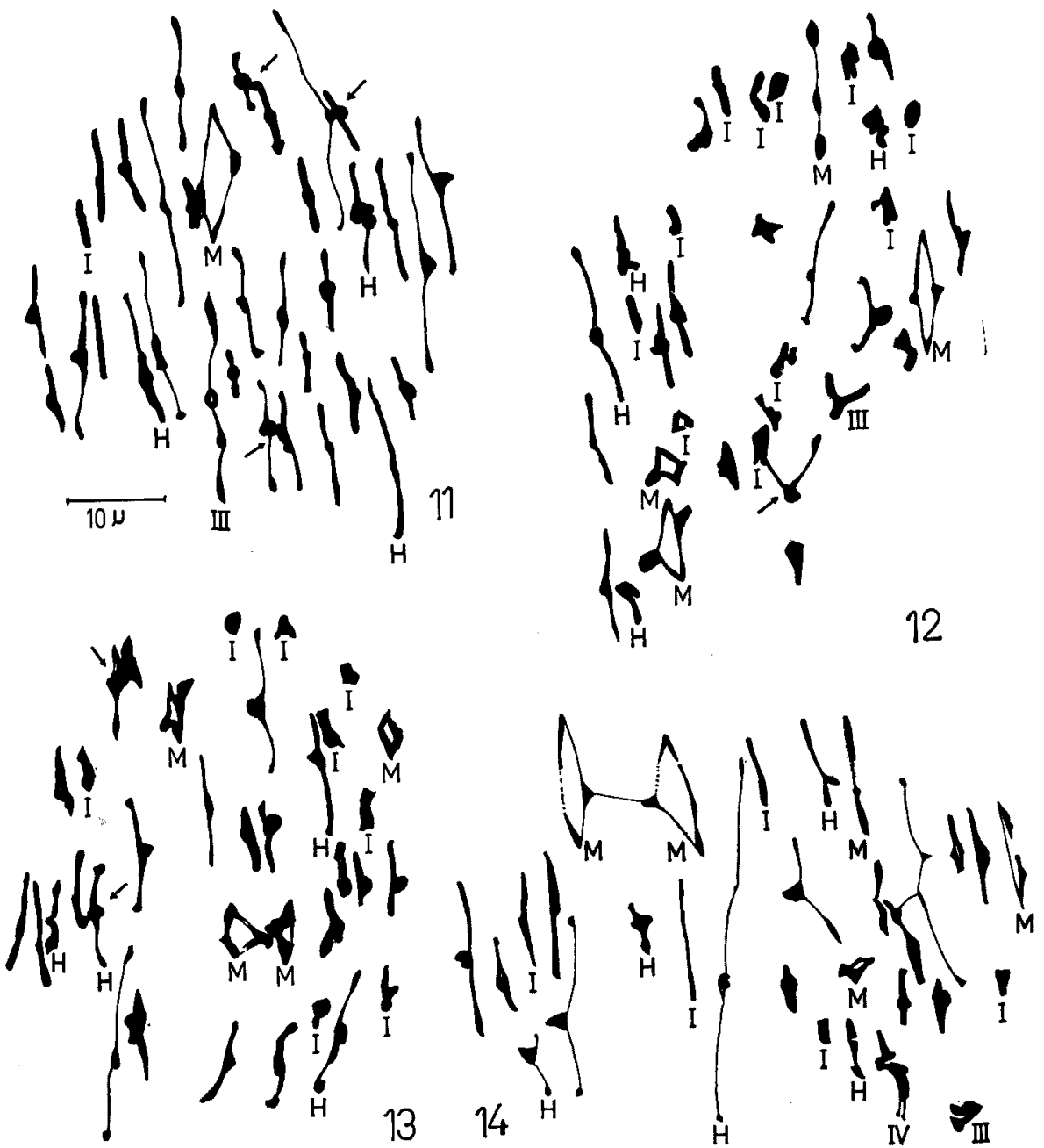

Figs. 11-14. First metaphases of $N$. lamellosa containing ring-bivalents (M). 11, $31 \mathrm{rod} \mathrm{II}+1 \mathrm{M}$ II+1 III+1 I $(n=34)$; note interstitial chiasmata in the linear trivalent, note aslo three associations of two bivalents each (arrows). 12, $20 \operatorname{rod} \mathrm{II}+4 \mathrm{M} \mathrm{II}+1 \mathrm{III}+11$ I $(\mathrm{n}=31)$; note one tripronged or $\mathrm{Y}$-shaped trivalent; arrow points to a non-disjunctional rod-bivalent. 13, 23 rod II $+4 \mathrm{M} \mathrm{II}+8 \mathrm{I}(\mathrm{n}=31)$; note two associations of two rod-bivalents each (arrows). 14,18 rod II + $5 \mathrm{M} \mathrm{II}+1 \mathrm{III}+1 \mathrm{IV}+5 \mathrm{I}(\mathrm{n}=29)$; note a bridge between two ring-bivalents $(\mathrm{M}-\mathrm{M})$ and another between two rod-bivalents $(\mathrm{A}-\mathrm{A})$.

extraordinarily numerous in $N$. lapillus also (Staiger 1954). An occasional asymmetrical bivalent possessed a visible AT constitution.

In first anaphases some half-bivalents were asymmetrical (Fig. 9), that is, carried distinctly unequal chromatids. As many as ten half-bivalents out of 35 of a set 
could have been of this kind. Although this might be a result of squashing it suggests the possibility that at least some of these cases reflect unequal translocation of chromosome segments.

\section{Ring-bivalents}

In roughly $49 \%$ specimens of $N$. lamellosa (63 out of 128) and $60 \%$ of $N$. lima (28 out of 46) in which prometaphases and first metaphases could be analysed an average of $29 \%$ (214 out of 750 plates) and $42 \%$ ( 83 out of 200 plates), respectively, contained a variable number of metacentric ring-bivalents. In extreme cases a maximum of 4-6 ring-bivalents occurred per plate in $N$. lamellos $a$ and one prometaphase of $N$. lima contained 14. Ring-bivalents were not seen consistently, however, in any one specimens of these species. They seemed to occur in all bivalent types

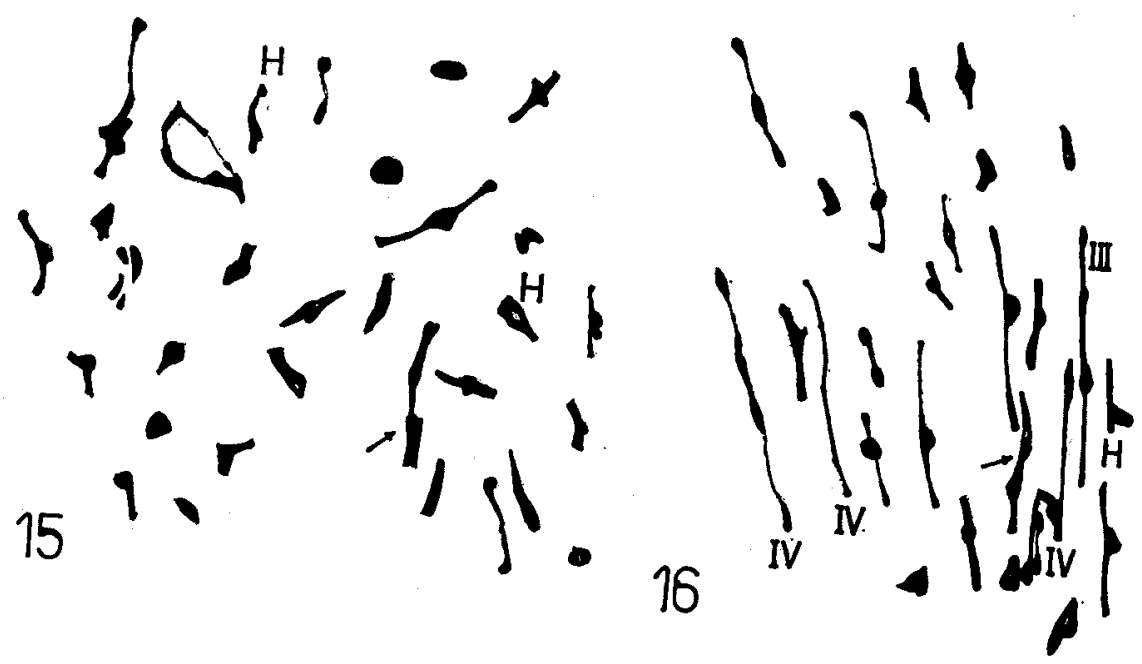

Figs. 15-16. First metaphases of $N$. lamellosa, both from the same animal. 15, polar view; note a ring of 4-6 chromosomes; arrow indicates a heteromorphic rod-bivalent with loss of a chromatid. 16, note two linear qudrivalents, one zig-zag quadrivalent and one linear trivalent and one association of two bivalents (arrow).

and in some cases the large and medium large ring-bivalents could be shown to be associated with decreased chromosome counts (Figs. 11-14) ranging from $n=29$ to 34 , only in $N$. lamellosa. The decreased numbers existed in only few (4\%) complements of about $9 \%$ (12 out of 128 ) specimens of this species. Univalents were generally observed in ring-bivalent containing plates of $N$. lamellosa and multivalent containing plates of all three species.

\section{Multivalents}

In all three species different types of closed and open multivalents were observed in only few oocytes and not all, of individual snails. Rings of four-to-six chromosomes (Figs. 15 and 20) showing adjacent and alternate orientation were observed in about $3 \%$ plates of $N$. lamellosa and $10 \%$ of $N$. lima (Table 1). They contained 
both terminal and interstitial chiasmata. Ring-multivalents could not always be distinguished from ring-bivalents along with which they were sometimes present in the same complement. Open linear and zig-zag chains of three and four chromosomes (Figs. 10, 11 and 16) occurred in 3-4\% plates of $N$. lamellosa only (Table 1). In these chisamata were terminal, subterminal or interstitial. In some cases alternate terminal and interstitial chiasmata held the multiples.

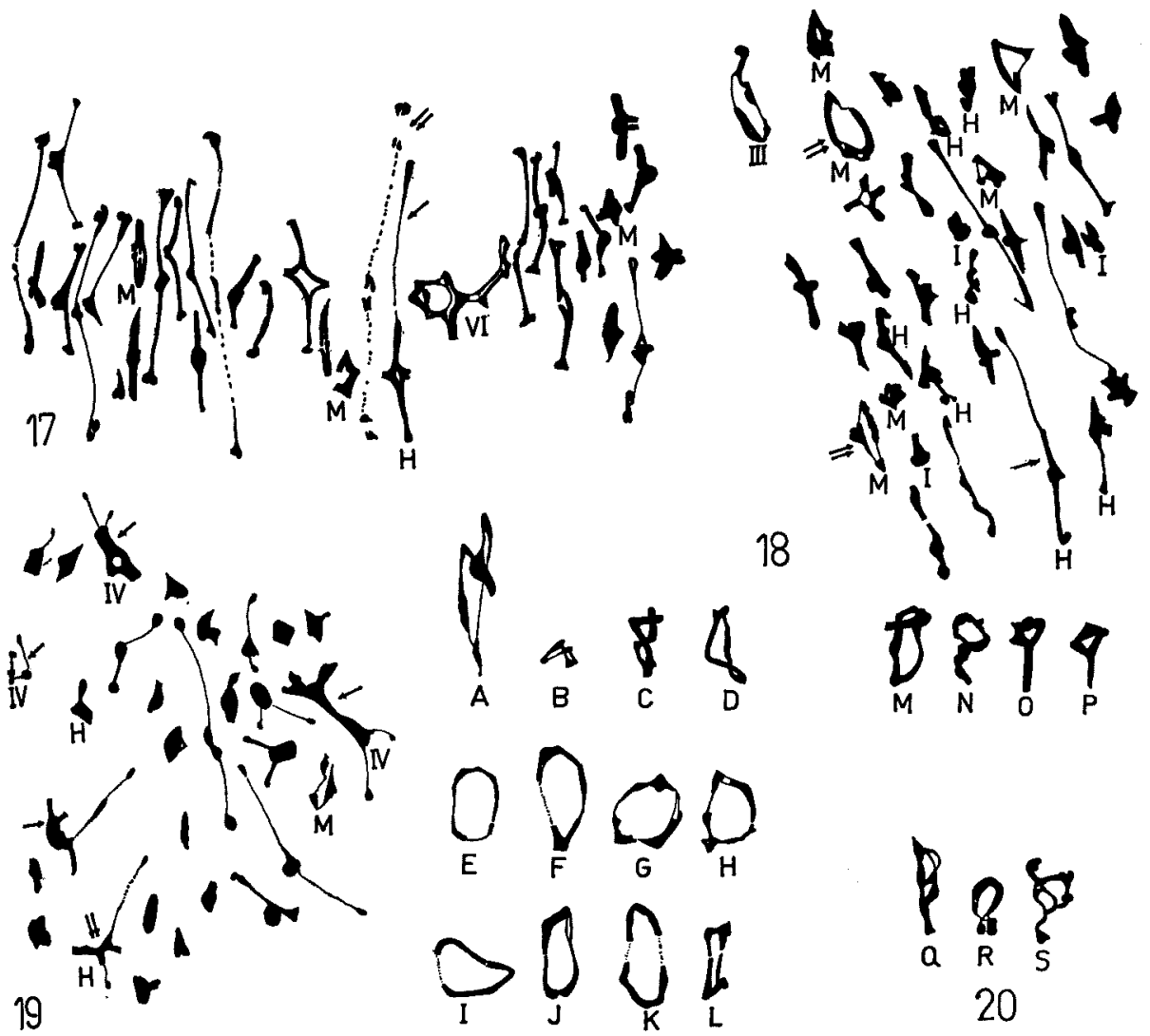

Figs. 17-20. 17-18. Prometaphases of $N$. lima. 17, 29 rod II+3 M II +1 VI (or association of 3 bivalents) $(n=35)$; the heteromorphic rod-bivalent marked by one arrow was frequently seen in this species; two arrows mark what most probably is a sex-bivalent. $18,26 \operatorname{rod} \mathrm{II}+6 \mathrm{M}$ II+1 III +3 I $(n=35)$; the heteromorphic rod-bivalent shown in Fig. 17 is also present (one arrow); note two heteromorphic ring-bivalents (two arrows) and a "Frying-Pan" trivalent at 10 o'clock position. 19, first metaphase of $N$. canaliculata; note associations of bivalents (one arrow) and one heteromorphic rod-bivalent showing inequality in the equatorial axis (two arrows). 20 , multivalents. A-D, rings of four giving alternate segregation; E-L, rings of four-to-six giving adjacent segregation; note interstitial as well as terminal chiasmata; M-P, "Frying-Pan" configurations; Q-S, multivalents showing inversion buckles.

Among the other occasionally observed configurations were "Frying-Pan" associations (Figs. 18 and 20), Y-trivalents (Fig. 12) and multivalents carrying apparent inversion buckles (Fig. 20). The "Frying-Pan" configurations appeared like 
Table 1. Incidence of multivalents in $N$. lamellosa and $N$. lima (out of 750 diakinesis-first metaphase plates of 128 specimens of $N$. lamellosa and 200 plates of 46 specimens of $N$. lima)

\begin{tabular}{|c|c|c|c|c|c|c|c|c|}
\hline \multirow[b]{2}{*}{$\begin{array}{c}\text { Type of } \\
\text { configuration }\end{array}$} & \multicolumn{4}{|c|}{ N. lamellosa } & \multicolumn{4}{|c|}{ N. lima } \\
\hline & $\begin{array}{l}\text { No. of } \\
\text { config. }\end{array}$ & $\begin{array}{l}\text { No. of } \\
\text { plates }\end{array}$ & $\begin{array}{c}\% \\
\text { plates }\end{array}$ & $\begin{array}{l}\text { No. of } \\
\text { indiv. }\end{array}$ & $\begin{array}{l}\text { No. of } \\
\text { config. }\end{array}$ & $\begin{array}{c}\text { No. of } \\
\text { plates }\end{array}$ & $\begin{array}{c}\% \\
\text { plates }\end{array}$ & $\begin{array}{l}\text { No. of } \\
\text { indiv. }\end{array}$ \\
\hline Discordant rings of 4 & 18 & 15 & 2.0 & 11 & 12 & 10 & 5.0 & 8 \\
\hline Zig-zag rings of 4 & 4 & 4 & .6 & 4 & 5 & 5 & 2.5 & 5 \\
\hline Rings of 4-6 & 2 & 2 & .3 & 2 & 5 & 5 & 2.5 & 5 \\
\hline Zig-zag chain of 4 & 3 & 3 & .4 & 3 & - & - & - & - \\
\hline Linear chain of 4 & 12 & 11 & 1.5 & 11 & - & - & - & - \\
\hline Linear chain of 3 & 15 & 14 & 2.0 & 10 & - & - & - & - \\
\hline $\mathrm{V}$ - trivalents & 19 & 17 & 2.3 & 6 & 2 & 2 & 1.0 & 2 \\
\hline $\begin{array}{l}\text { Frying-Pan } \\
\text { associations }\end{array}$ & 8 & 8 & 1.1 & 8 & 5 & 4 & 2.0 & 4 \\
\hline Y-trivalents & 2 & 2 & .3 & 2 & 2 & 1 & .5 & 1 \\
\hline Inversion multivalents & 3 & 3 & .4 & 3 & - & - & - & - \\
\hline
\end{tabular}

circles and triangles each carrying a univalent. There were two triangular and one circular configuration each with two arms in $N$. lamellosa and one five-pronged structure in $N$. lima. Few V-shaped trivalents were also observed but mostly in $N$. lamellosa. These were smaller in size than the V-trivalents of $N$. lapillus observed by Staiger (1954).

\section{Discussion}

The occurrence, in the three species of Nucella, of numerous asymmetrical rod-bivalents (in which pairing arms were unequal and chiasmata asymmetrically placed) can be interpreted in more than one way. Most of these were probably only a result of disproportionate stretching of free arms during the prometaphase stage. Yet the possibility that intrachromosomal changes, such as pericentric inversions or centric-shifts, have occurred in some can not be altogether ruled out. Asymmetrical bivalents of this kind were reported to be extraordinarily numerous in $N$. lapillus and Staiger (1954) considered the possibility that they were a result of pericentric inversion. Bivalents which are visibly composed of paired combinations AT, TA, AS and MS chromosomes must be an outcome either of heterozygous pericentric inversion or else of pairing between partly non-homologous chromosomes. Such bivalents have been seen also in the marine mussels Mytilus edulis and $M$. californianus where pericentric inversions have been postulated to account for them (Ahmed and Sparks 1970b).

In the occasional prometaphases of $N$. lamellosa in which numerical decreases existed when large and medium sized ring-bivalents occurred, centric-fusions must have taken place. A centric-fusion involves a reciprocal translocation between two non-homologous acrocentrics to produce a new metacentric and simultaneously a small centric fragment which is usually assumed to be rapidly lost. That a poly- 
morphism for centric-fusions may occur in $N$. lamellosa is also suggested by the occurrence of V-shaped trivalents in some individuals. These would be expected in fusion heterozygotes.

In the genus Nucella, $N$. lapillus is outstanding for its Robertsonian pattern of centric-fusions. In this species a decrease in chromosome number has occurred from 36 to 26 consequent on the occurrence of five centric-fusions and numerous heterozygotic numbers are aslo realized (Staiger 1954). The precise form of the chromosome complements in this species is closely correlated with the microhabitat. The two homozygotic forms, 36 and 26, occur respectively on sheltered and exposed coastal shores; morphs with intermediate numbers occupy shores of intermediate wave exposure. No such correlation has been found in $N$. lamellosa, $N$. lima and $N$. canaliculata, although specimens of all three species were deliberately collected from sheltered as well as exposed shores.

It has been customary to interpret multiple associations in hybrids as evidence of interchange heterozygosity. Indeed Staiger (1955) interpreted the multiple associations in $N$. lapillus in this way. White (1957 and 1969), however, is of the opinion that the occurrence of multiples is not necessarily to be interpreted as evidence of interchange heterozygosity. Instead he regards them as constituting evidence for his hypothesis of "end duplications" as a consequence of which a given end can associate with a variety of other ends producing multiples with strictly terminal chiasmata. John and Lewis (1965 and other papers) have, however, argued that non-chiasmate and non-homologous associations of a persistent kind may also account for the production of multiple associations in certain circumstances. In the three species of Nucella, the evidence from the occurrence of rings of 4-6 chromosomes, open linear and zig-zag trivalents and quadrivalents together with the presence of univalents may be interpreted in terms of either interchange heterozygosity or associations of non-homologous or at best partly homologous chromosome ends. Multivalents have been found to occur in a limited number of plates of $N$. lamellos $a$ and $N$. lima so that the condition can be considered at best only to be floating in the populations. In $N$. lapillus about $1 \%$ of the snails examined were entire germ-line interchange heterozygotes (Staiger 1955).

The seven species of Nucella which have been investigated thus far have possessed different chromosome numbers: $\mathrm{n}=13$ to 18 in N. lapillus (Staiger 1954)); $\mathrm{n}=30$ in $N$. luteostoma, $N$. bronni and $N$. clavigera (Nishikawa 1962) and $\mathrm{n}=35$ in $N$. lamellosa, N. lima and $N$. canaliculata (Ahmed and Sparks 1970a). Although neither of the numbers 30 or 35 is an exact multiple of the $n=13-18$ series they are close to it. Now, doubling of number could have been achieved in these snails by either of two ways:

1. by tetraploidization and this means duplication of DNA values also;

2. by simple breakage through the centromere (misdivision or centric-fission) which, of course, would not lead to any change in DNA content. Ford (1965) seems to think that fission may be responsible for bringing about the change from $\mathbf{n}=13$ to 18 in $N$. lapillus although Staiger himself favoured fusion.

Whether the $\mathrm{n}=30$ and 35 species arose by process 1 or 2 can not be answered though an answer might be provided by accurate determinations of DNA values. If chro- 
mosome size is any indication of species relationship then it may be significant that bivalents of the three species examined measured half as much in length as those of $N$. lapillus. If $N$. lapillus is the ancestral form, or close to it, then the distribution of the original amount of genetic material in a doubled number as a result of fission could explain both the size and number differences.

\section{Summary}

The chromosome number in the marine gastropods Nucella lamellosa, $N$. lima and $N$. canaliculata is $70(\mathrm{n}=35)$. Chromosome analysis of about two hundred individuals from natural populations gave evidence for the occurrence of:

1. pericentric inversions leading to the production of heteromorphic bivalents.

2. centric-fusions (only in $N$. lamellosa) resulting in the formation of large and medium-large metacentric ring-bivalents in place of rod-bivalents in only few cells $(4 \%)$ of individual snails.

3. Floating interchange heterozygosity or associations of non-homologous or partly homologous chromosomes giving rise to rings of 4-6 chromosomes, open linear and zig-zag quadrivalents and trivalents and univalents occurring in a limited number of plates.

In none of these cases, however, is there any evidence for a regular polymorphism associated with differences in microhabitat equivalent to that known in $N$. lapillus.

\section{Acknowledgments}

I am thankful to Professor Albert K. Sparks and Dr. D.W. Hagen of the College of Fisheries, University of Washington, Seattle for helping me in the present investigation. Grateful appreciation is expressed to Professor M.J.D. White of the Department of Genetics, University of Melbourne, for kinldy accepting to read one of the drafts based on the results of this investigation and for his most valuable criticism of the manuscript. Finally I am extremely thankful as well as indebted to Professor Bernard John, presently at the Australian National University, for his extensive help in the writing of this paper and for his most critical comments. This study was partially supported by the Ecology Training Grant No. 11-5250 accorded to the Department of Zoology, University of Washington, Seattle.

\section{References}

Ahmed, M. and Sparks, A. K. 1970a. A note on the chromosome number and interrelationships in the marine gastropod genus Thais of the U.S. Pacific coast. Veliger 12: 293-294.

- 1970b. Chromosome number, structure and autosomal polymorphism in the marine mussels Mytilus edulis and M. californianus. Biol. Bull. (Woods Hole) 138 (1): 1-13.

Ford, E. B. 1965. Ecological Genetics. London: Methuen.

John, B. and Lewis, K. R. 1965. Genetic speciation in the grasshopper Eyprepocnemis plorans. Chromosoma (Berlin) 16: 308-344.

Meredith, R. 1969. A simple method for preparing meiotic chromosomes from mammalian 
testis. Chromosoma (Berlin). 26: 254-258.

Nishikawa, S. 1962. A comparative study of chromosomes in marine gastropods with some remarks on cytotaxonomy and phylogeny. J. Shimonoskei Coll. Fisher. 11: 149-186.

Staiger, H. 1954. Der Chromosomendimorphismus beim Prosobranchier Purpura lapillus in Beziehung zur Ökologie der Art. Chromosoma (Berlin) 6: 419-478.

- 1955. Reciproke Translocation in natüralichen Populationen von Purpura lapillus. Chromosoma (Berlin.) 7: 181-197.

White, M.J.D. 1957. Some general problems of chromosomal evolution and speciation in animals. Surv. Biol. Prog. 3: 109-147.

- 1969. Chromosomal rearrangements and speciation in animals. Ann. Rev. Genet. 3: 75-98. 